\title{
ENTRE O TODO E O SUJEITO: CONDIÇÕES PARA A CONSTRUÇÃO DE UMA AGENDA POSITIVA DE DIREITOS HUMANOS
}

\section{BETWEEN THE TOTAL AND THE SUBJECT: CONDITIONS TO FORMULATE A POSITIVE HUMAN RIGHTS AGENDA}

Ivan Pinheiro Figueiredo

Mestrando em Direito pela Universidade Estadual Paulista - UNESP.

E-mail: ivanpfigueiredo@gmail.com

Recebido em: 09/04/2015

Aprovado em: 19/04/2016

Doi: $10.5585 / \mathrm{rdb} . v 14 i 6.257$

\begin{abstract}
RESUMO: Procura-se discutir a relação entre o sujeito e a totalidade a partir das visões de Søren Kierkegaard, e a respectiva interpretação de sua obra feita por Theodor Adorno, para a partir daí desenvolver raízes teóricas de atuação política em relação à efetivação de direitos humanos. A partir da virada ao subjetivo operada pela filosofia kierkegaardiana em "Temor e tremor", estabelecer a capacidade de ação política transformadora inserida em um contexto com pretensões hegemônicas e conservadoras.
\end{abstract}

Palavras-chave: Kierkegaard. Direitos Humanos. Totalidade. Subjetividade.

ABSTRACT: This article discusses the relation between the subjectivity and the totality from the perspectives of Søren Kierkegaard, and the interpretation of his work made by Theodor Adorno, to thereafter develop theoretical roots of political action in relation to the implementation of human rights. From the turn to the subjective operated by kierkegaardian philosophy in "Fear and trembling", establish the ability of transforming political action embedded in a conservative context with hegemonic pretensions.

Keywords: Kierkegaard. Human Rights. Totality. Subjectivity.

SUMÁRIO: Introdução; 1 . O todo e o sujeito em Kierkegaard; 2. O pensamento universal e a lógica totalizadora; 3 . A construção de uma agenda positiva para os direitos humanos;

Bibliografia

\section{O TODO E O SUJEITO EM KIERKEGAARD}

Em seu livro "Temor e Tremor", Søren Kierkegaard, escrevendo sob o pseudônimo de Johannes de Silentio, trata da possibilidade de ocorrência de uma suspensão teleológica do ético. Valendo-se da passagem bíblica sobre Abraão e Isaac, pai que recebe a incumbência de assassinar seu filho, o dinamarquês procura conciliar o universal e o indivíduo. A questão está no paradoxo enfrentado por Abraão, consistente na necessidade de conciliar o ético ${ }^{1}$, universal, exprimido no mandamento de que um pai deve amar seu filho mais do que a si, com o rompimento operado por um ato de fé necessariamente individual.

${ }^{1}$ O termo "moralidade" é utilizado na tradução brasileira de "Temor e tremor", ao passo que a tradução para o inglês (KIERKEGAARD, 2013) utiliza o termo "Ethical", que traduz-se em "ética", utilizada como referência.

Revista de Direito Brasileira | São Paulo, SP | v. 14 | n. 6 | p. 80 - 88 | maio/ago. 2016 
A situação torna-se paradoxal pois a suspensão do ético precisa ser operada por agente que inserido nos limites normativos do ético, precisa superá-los. O caso é distinto daquele enfrentado por "heróis épicos", como Agamemnon, rei grego cujo sacrifício da filha Ifigênia, malgrado seja capaz de gerar sofrimento ao pai, é executado com o fito de "salvar" um povo, e portanto cingido pelos limites do ético. O caso de Abraão é completamente distinto. Nas palavras de Kierkegaard (2008, p. 53), Abraão "[n]ão está agindo para a salvação de um povo, nem para defender a ideia de Estado, nem mesmo para apaziguar os deuses zangados". Enquanto a ação de Agamemnon pode ser compreendida por toda a comunidade, que entende a "nobre ação de consentir, no interesse geral, o sacrifício de sua virgem e amada filha" (KIERKEGAARD, 2008, p. 51), Abraão desafia o dever ético de amor em relação a seu filho.

A abstração do ético, compreendido como requisito moral de validade universal instituído na forma de um relicário de normas e princípios objetivos, gerais e racionalmente inteligíveis (SCHRAG, 1959), é barrada pela concretude do comportamento que desafia o universal. Kierkegaard reconcilia os pontos ao fazer encontrar no Indivíduo a razão para a suspensão teleológica do universal. Abraão é, de acordo com a concepção kierkegaardiana, a ruptura da ética universal enquanto totalidade de normas de conduta reconhecíveis operada em favor de um universal assentado no interior do indivíduo. A partir daí, o etéreo universal do qual é constituído o ético precisa ser apropriado pelo concreto, vez que "o indivíduo concreto é a fundação e o portador do universal, e o universal tem validade apenas na medida em que emerge do concreto e encontra o indivíduo existente" (SCHRAG, 1959, p. 67). ${ }^{2}$

Torna-se clara a pretensão de Kierkegaard perfurar a esfera de uma totalidade ética através da suspensão teleológica de sua validade normativa; à pergunta sobre qual é então a vida do indivíduo que sofre essa suspensão, responde: "existe como Indivíduo que se opõe ao geral" (KIERKEGAARD, 2008, p. 65). O momento de contradição total resultante do contraposto entre a ética universal e a exigência de cariz religiosa que impõe a suspensão do ético é superada, em Kierkegaard, através do salto realizado por Abraão para atender a uma necessidade decorrente da fé. Na posição em que foi posto, não há qualquer mediação possível para Abraão, que sequer pode falar. A figura da deidade, ausente no paganismo, incorpora o dever maior que enseja a suspensão do ético. A divindade, todavia, habita lugar distinto do geral, o que torna necessário o silêncio de Abraão, visto que "quanto falo, dou expressão ao geral, e se mantenho calado, ninguém pode me entender. Quando Abraão quer exprimir-se no geral, é-lhe preciso dizer que a sua situação é aquela da dúvida religiosa, pois não dispõe de expressão mais elevada, vinda do geral, que fique acima do geral que ele ultrapassou" (KIERKEGAARD, 2008, p. 54).

O "salto" dá-se entre as esferas do ético e do religioso. O indivíduo supera a totalidade ética para reencontrá-la na esfera religiosa, conectada com o divino. A pretensão kierkegaardiana de combater o pensamento sistemático, atingindo no subjetivo o epicentro de significação, de alguma maneira, todavia é falseada pela resposta construída na hierarquização das esferas do ético e do religioso; a total ruptura do universal ético conduz à esfera do religioso, localizada somente depois da superação do ético. A subjetividade não se encerra em si mesma, mas encontra novo significado no objetivo que constitui a religião; se Abraão irrompe o ético, é porque encontrou a esfera do religioso. Se Kierkegaard pretendia fugir à sistematicidade, encontrou abrigo num modelo sistematicamente estruturado, de hierarquia e de passagens de uma esfera à outra. Aí está o problema da sistematização em torno da doutrina do "salto" entre esferas sucessivas, notado por Adorno ao apontar que o esquema das esferas não é algo deduzido, mas são elas postas umas junto às outras, como as ideias platônicas, e representam estágios no caminho da vida, ultrapassando-se uma após a outra (ADORNO, 2006, p. 116).

${ }^{2}$ No original: "The concrete individual is the foundation and the bearer of the universal, and the universal has validity only insofar as it emerges from the concrete encounters of the existing individual".

Revista de Direito Brasileira | São Paulo, SP | v. 14 | n. 6 | p. 80 - 88 | maio/ago. 2016 
Não obstante, as esferas, enquanto momentos antitéticos do processo dialético inaugurado pelo indivíduo na reconstrução nele mesmo do sentido ontológico, retratam a contradição irresolúvel que escapa ao conceito, permanecendo como signos da precariedade de uma existência na qual o sentido ontológico está oculto. Desse modo, "se Kierkegaard busca a ontologia exclusivamente na dialética da subjetividade, esta ontologia não pode ser completamente reproduzida na frágil estática daquela hierarquia de esferas. Suas rupturas não são senão as marcas que deixa um movimento que a própria hierarquia efetua" (ADORNO, 2006, p. $124)^{3}$. Se em "Temor e tremor" havia o embate entre o ético total e a exceção, privilegiando-se a saída subjetivadora, torna-se possível unir a própria figura humana à exceção que escapa ao total, o que conduz à conclusão de Adorno (2006, p. 133) no sentido de que "em Kierkegaard, a imagem do homem é idêntica à da "exceção": emancipando-se da contingência, do anonimato, da universalidade coisificada". Resta necessário perguntar se "em nome da transcendência das esferas extremas, inimigas da pessoa, não acaba toda a ética, inclusive a burguesa-privada, que seus [de Kierkegaard] escritos 'éticos' representaram, submetida ao veredito e à ironia da 'exceção"” (ADORNO, 2006, p. 133). ${ }^{5}$

A leitura laicizada de Kierkegaard realizada por Adorno, apartada da tradicional interpretação de cariz teológica, encontra no subjetivo, para além da reconciliação com o universal, a chave para ultrapassar eventuais obstáculos totalizadores. Tanto Kierkegaard como Adorno encontrariam no sujeito o "movimento interior do qual o caráter constituinte da elaboração conceitual confronta-se com uma resistência que vem da reflexão empírica e tem estatuto de algo real que afeta o pensamento" (SAFATLE, 2013, p. 211). Na raiz, o pensamento dos dois autores, revelada na leitura adorniana de Kierkegaard, compartilha a busca por "constituir um conceito de sujeito capaz de servir de fundamento para a crítica à noção hegemônica de subjetividade" (SAFATLE, 2013, p. 212).

Diante da ciência de que o pensamento contemporâneo, ao invés de atingir as raias da emancipação da razão, teria seguido o sentido contrário, caracterizado pelo emergir de totalitarismos das ditaduras e das sociedades massificadas, a interioridade kierkegaardiana, devidamente laicizada, poderia oferecer um refúgio extraterritorial. Além do refúgio, "a interioridade podia ser o lugar de uma resistência: a innere Emigration, a emigração interna, a recusa radical e absoluta do sujeito de mitmachen, de colaborar com o inimigo" (ROUANET, 2013, p. 154). A leitura de Kierkegaard feita por Adorno, então, poderia localizar a salvação do indivíduo contra as investidas do sistema totalizador no próprio indivíduo, na relação modelar estabelecida entre o caso e o conceito, entre a filosofia e as artes.

\section{O PENSAMENTO UNIVERSAL E A LÓGICA TOTALIZADORA}

A possibilidade de transbordar os limites de um ético universal, totalizador, a partir da perspectiva subjetiva, tese fundamental da filosofia kierkegaardiana e tratada especificamente em "Temor e tremor", abriu espaço para a equiparação, por Adorno, do indivíduo à exceção, em um

\footnotetext{
${ }^{3}$ No original: "Si Kierkegaard busca la ontología exclusivamente en la dialéctica de la subjetividad, esta ontología no puede ser completamente reproducida en la frágil estática de aquella jerarquía de las esferas. Sus roturas no son sino las marcas que deja un movimiento que la jerarquía misma efectúa”.

4 No original: "en Kierkegaard, la imagen del hombre es idéntica a la de la «excepción», para él, el hombre solo existe humanamente cuando constituye una excepción: emancipándose de la contingencia, del anonimato, de la universalidad cosificada".

${ }^{5}$ No original: "en nombre de la trascendencia de las esferas extremas, enemiga de la persona, no queda toda la ética, incluida la burguesa-privada, que sus escritos «éticos» representan, sometida al veredicto y a la ironía de la «excepción»”.
}

Revista de Direito Brasileira | São Paulo, SP | v. 14 | n. 6 | p. 80 - 88 | maio/ago. 2016 
movimento de emancipação da universalidade coisificada. A dialética negativa de Kierkegaard, despida de uma síntese pacificadora e que remonta à interpretação do pensamento socrático em sentido completamente distinto daquele trilhado por Hegel, é a maior expressão da linha de pensamento que procura fornecer espaço para o rompimento do universal (ROUANET, 2013).

A crítica ao pensamento kierkegaardiano, que indica que o interior no qual se localizaria a saída para o universal totalizador somente poderia ser aquele pertencente ao filósofo-rentista, visto que o próprio Kierkegaard experimentou uma vida burguesa, segregada do processo produtivo, ressoa na tentativa de utilização de sua filosofia como base de trabalho teórico. Ainda assim, a "própria radicalidade da filosofia de Kierkegaard, que recusa qualquer conivência com o existente, tanto em suas estruturas eclesiásticas como seculares, permite entrever os contornos de uma intuição justa sobre a história e a natureza" (ROUANET, 2013, p. 151). Justamente a radicalidade do pensamento do filósofo dinamarquês possibilita entreabrir a porta filosófica ao seu pensamento.

Sendo possível rebentar, no contexto massificante de um ético totalizador, a capacidade de suspendê-lo em favor de uma visão pautada no indivíduo, que eleva-se sobre o "universal", passa a ser viável a defesa de uma ressignificação a partir de dentro da massa. O velho embate sobre uma ação que legitimamente corrói e ultrapassa os limites contingenciais socialmente instituídos dos quais ela mesmo deriva, tratada por Habermas (2011) pelo nome de "ação moralmente autorreferencial", em Kierkegaard é resolvida pela virada ao subjetivo, que ultrapassa a abstração do universal para superá-lo através da concretude da experiência pessoal, afinal, "no abstrato, diante de um favor, todos possuem os mesmos direitos. Esquecem-se a tribulação, a angústia, o paradoxo" (KIERKEGAARD, 2008, p. 59). ${ }^{7}$ A dialética kierkegaardiana, consistente no movimento que a subjetividade efetua para recuperar por si mesma e em si mesma o 'sentido' e desligada de qualquer conteúdo ôntico positivo, convertendo todo o ser em ocasião de si mesma, subtrai a definição material; ela é imanente, e sua imanência, infinita (ADORNO, 2006, p. 40 e ss.).

A concretude descoberta no subjetivo, orientadora dos processos de significação e capaz de fazer superar o pensamento totalizador, então tratada como ponto de partida para um pensamento dirigido para dissolver as categorias ditas universais, pode ser transposta como um modelo filosófico para o trato de problemas ligados à concreção de direitos humanos baseado na figura do agente relativamente expungido da determinação em razão de sua constituição sóciobio-psíquica.

Nesses termos, enxerga-se o direito inserido e ao mesmo tempo produto de uma sociedade organizada em torno de um capitalismo totalizante e colonizador, capaz de tornar a produção econômica e a estratificação social dela decorrente em alicerce e única fonte de explicação da história política e intelectual (MARX; ENGELS, 2012). A racionalidade econômica, enquanto centro conferidor de significação às relações sociais, baseia-se nos "princípios, comportamentos e as instituições de economia formal e do mercado total, do "Mercado" com "M" maiúsculo", fazendo com que o capital empurre "a economia mercantil para

\footnotetext{
${ }^{6} \mathrm{O}$ problema é recorrente. Ao tratar das raízes filosóficas de uma teoria do discurso, Laclau (2003) desenha três "momentos" do estruturalismo - a fundação da linguística estrutural por Saussure, a radicalização do formalismo estrutural pelas escolas de Praga e Copenhagen e o desenvolvimento de uma teoria da hegemonia - e aponta que em todos os casos, há permanente confronto com as aporias internas que organizações estruturais demonstram e a impossibilidade de superá-los dentro do sistema de regras que preside sua constituição.

7 Como anota Adorno: "Como adversario de la doctrina hegeliana del espíritu objetivo, Kierkegaard no desarrollo ninguna filosofía de la historia. Con la categoría de "persona» y la historia interior de la persona quiere expulsar la historia exterior del dominio de su pensamiento. Pero la historia interior de la persona se relaciona antropológicamente con la exterior en la unidad de la «especie »" (ADORNO, 2006, p. 44). [Como adversário da doutrina hegeliana do espírito objetivo, Kierkegaard não desenvolve nenhuma filosofia da história. Com a categoria de "pessoa" e a história interior da pessoa quer expulsar a história exterior do domínio de seu pensamento. Mas a história anterior da pessoa se relaciona antropologicamente com a exterior na unidade da "espécie".
} 
a totalização do mercado. Até a moral se desliga dela e perde sua normatividade, porque a economia se apropria do Mercado para ser o dispensador de valores" (RUBIO, 2013, p. 6-7).

O próprio desenvolvimento temporal do modo de produção capitalista, com a criação de novas necessidades no lugar de antigas, cuja satisfação demandaria produtos de países e climas longínquos, "aglomerou populações, centralizou os meios de produção e concentrou em poucas mãos a propriedade", o que resultou numa centralização política e a reunião de modos de vida distintos em "uma nação, um governo, uma lei, um interesse nacional de classe, uma fronteira aduaneira" (MARX; ENGELS, 2012, p. 48-49).

Ou seja, a massificação e a totalização de uma forma de pensamento são inerentes à forma de organização produtiva capitalista. A instituição mesmo da forma dinheiro, como responsável por unificar e transformar coisas físicas em metafísicas, visto que reflete "aos homens as características sociais de seu próprio trabalho como características objetivas dos próprios produtos de trabalho, como propriedades naturais sociais dessas coisas e, por isso, também reflete a relação social dos produtores com o trabalho total como uma relação social existente fora deles, entre objetos", é pressuposto para a circulação de mercadorias e somente funciona a partir da estabilização de determinadas formas de vida social das quais erige o processo de conversão da mercadoria em valor, pois "as formas que certificam os produtos do trabalho como mercadorias e, portanto, são pressupostos da circulação de mercadorias, já possuem a estabilidade de formas naturais da vida social, antes que os homens procurem dar-se conta não sobre o caráter histórico dessas formas, que eles já consideram imutáveis, mas sobre seu conteúdo", do que resulta que "somente a análise dos preços das mercadorias levou à determinação da grandeza do valor, somente a expressão monetária comum das mercadorias levou à fixação de seu caráter de valor" (MARX, 1987, sem itálico no original). Desse modelo de organização é possível deduzir a integração de sistemas sociais diversos em um sistema global, do qual emana a significação limitadora e totalizadora dos processos da vida: "[d]eclarar guerra a diversidade e apostar pela uniformidade de culturas e de cultivos se considera a melhor estratégia, enquanto que a arma com que se executa é o exercício de uma força virulenta disfarçada sob a roupagem do livre mercado e também amparado pela força militar" (RUBIO, 2013, p. 11).

Esse modelo de pensamento recorreria ao modo de organização capitalista para dele desprender o significado de todas as relações desenvolvidas no interior de sociedades submetidas a essa economia. No caso do direito, a secularização da concepção teológica, com o dogma divino substituído pelo direito humano, à Igreja sobrevindo o Estado, foi possível criar normas jurídicas, originárias de fatos econômicos, capazes de dar feição de codificação formal ao arcabouço que tinha por finalidade garantir a igualdade diante da lei como forma de estatuir a competição e a concorrência como bases da organização social. E mesmo sobrevindo a reinvindicação por igualdade material, compreendeu-se que "deixando essa questão sobre o terreno 'do direito' não se poderia de maneira nenhuma eliminar os males engendrados pelo modo de produção do capitalismo burguês e, sobretudo, pela grande indústria moderna", o que fez "abandonar completamente o terreno jurídico-político e a declarar que toda luta política era estéril" (ENGELS, 1980, p. 3). Em suma, "uma relação jurídica toma de empréstimo um conteúdo que ela própria não é capaz de engendrar, espelhando uma relação econômica" (GIANNOTTI, 1980, p. 10).

Sob essa perspectiva, a luta política empreendida no interior ou a partir de instituições jurídicas carece de sentido e torna-se completamente estéril. Encravada num sistema completo, totalizador e de pretensão universalista, o direito seria incapaz de romper com a trama social da qual origina. Na sistematização axiomática do direito como quadro de coesão formal estaria encoberta uma função estratégica de reprodução ampliada do capitalismo: o direito atuaria como estabilizador das regras de transformação social; "seu caráter sistemático, com base em normas 
abstratas, gerais, formais e estritamente regulamentarizadas" comportaria "suas próprias regras de transformação, fazendo assim com que suas modificações se tornem transformações reguladas no seio de seu sistema (papel notadamente da Constituição)" (POULANTZAS, 1980, p. 80).

Os direitos humanos, compreendidos como a forma ocidental hegemônica de luta por dignidade humana, seriam produtos da lógica totalizadora e colonialista do modo de produção capitalista (FLORES, 2005). Ao invés de exercerem o papel de barreira contra a ação do mercado, seria o mercado auto-regulado, nos limites da máxima eficiência e da redução de custos econômicos o operador e aplicador dos direitos. Direitos humanos são, com efeito, produto cultural surgido no ocidente em função da necessidade de justificação ideológica das expansões coloniais pelo globo e ainda para enfrentar a globalização das injustiças que a agenda expansionista produziu.

A saída que pretendeu romper com a visão universalista dos direitos humanos de origem europeia, burguesa e economicamente orientada foi pensada com base na visão de que não se pode condensar direitos em conceitos acadêmica e hegemonicamente formulados, mas sim no contexto e na concretude da multiplicidade de visões distintas acerca da dignidade. $\mathrm{O}$ desenvolvimento de uma teoria crítica dos direitos humanos, nessa esteira, está necessariamente comprometido com a realização de um pensamento novo, na "humanização do humano", "não no que se refere à imposição universal de algum conteúdo aceito por todos, mas na potencialização de nossa capacidade cultural de criatividade e postulação de alternativa ao existente" (FLORES, 2005, p. 42). ${ }^{8}$

\section{A CONSTRUÇÃO DE UMA AGENDA POSITIVA PARA OS DIREITOS HUMANOS}

O projeto universalista de expansão do modo de produção capitalista, responsável por dizimar formas de vida distintas e pela criação de um aparato capaz de internalizar e homogeneizar, sob a rubrica de universais, visões de direitos completamente distintas entre si, alcançou sucesso inegável. O incremento de técnicas de comunicação veloz e invasiva, com grande capacidade de dispersão de informações propagandísticas para um grande número de pessoas em tempo extremamente curto resultou em um nivelamento cultural nunca antes experimentado. A denúncia sobre a forma de organização de direitos em torno do eixo hegemônico, que se articula em razão e com o intuito de manter a sua matriz europeia, branca, capitalista, burguesa, masculina, patriarcal e cristã nunca mereceu tanta atenção.

No entanto, se há algo a ser extraído da visão kierkegaardiana sobre a possibilidade de ruptura do universal a partir da reflexão calcada no sujeito, na dialética entre a história subjetivada e a externa, no constante movimento interior do indivíduo capaz de ressignificar a totalidade em razão da visão subjetiva, que escapa ao todo, esse algo está contido na possibilidade de mudança a partir de dentro, no revolvimento do universal pelo ser humano dotado de capacidade de subjetivar o real universalizante e de superá-lo. ${ }^{9}$

\footnotetext{
${ }^{8}$ No original: "No en lo que se refiere a la imposición universal de algún contenido aceptable por todos, sino en la potenciación de nuestra capacidad cultural de creatividad y de postulación de alternativa a lo existente".

9 À margem, cumpre anotar que as diferenças entre o pensamento de Joaquín Herrera Flores e de Habermas não sejam tão grandes quanto possa parecer. Herrera Flores fala que: "Pensar los derechos humanos, desde este plano de inmanencia, nos lleva a integrar dentro de su concepto, no solo formas y procedimientos que reúnen a individuos, grupos o Estados bajo la forma de denuncias mutuas ante las Cortes Internacionales de Derechos Humanos, sino también la exigencia de construcción de lugares de encuentro en que todas y todos los que participen puedan hacer valer sus propuestas y sus diferencias. Lugares de encuentros de seres humanos empoderados, es decir, de individuos y grupos que gocen de un conjunto de condiciones basadas en tres especificaciones de la igualdad: igual valor, igual racionalidad e igual autoridad" (FLORES, 2005, p. 45 - alguns itálicos não constam no original). Habermas defende: "Una distribución igual de derechos exclusivamente formal no puede garantizar por sí sola la autonomía pública de todos los ciudadanos. Una "igualdad jurídica" entendida en términos materiales - igualdad en el contenido de los derechos - exige que todos puedan tener las mismas oportunidades para hacer uso, fácticamente, de esos derechos Revista de Direito Brasileira | São Paulo, SP | v. 14 | n. 6 | p. 80 - 88 | maio/ago. 2016
} 
O sujeito capaz de escapar do universal, portanto, pode obstar a reprodução sistemática do conhecimento totalizador. Encontrar no sujeito a possibilidade de romper com a dinâmica autofágica e auto reprodutora típica do sistema capitalista, permite, com efeito, tratar as instituições, como a lei e o Estado, de uma nova perspectiva.

A figura do Estado, tradicionalmente criticada por atuar como braço operacionalizador da vontade das classes socialmente hegemônicas, a partir de um pensamento voltado à capacidade humana de criação subjetiva, pode ser concebida como mecanismo de tutela de direitos até então menoscabados. Ao revés do quanto enunciado por Engels (1980), a luta política e jurídica não pode ser tomada como estéril e carente de sentido, mas sim como eixo principal para a transformação social. O problema quanto à autoreprodutividade do sistema eficientista e desconectado do ser humano do qual o Estado é longa manus pode ser então superado a partir da confiança na existência do ser humano dotado de criatividade, presente e capaz de interferir nos processos do qual participa.

É claro que a proposição toma cariz puramente idealista se as condições materiais de ação política, meio através do qual as demandas por direitos assumem caráter público e podem ser encampadas como fins a serem desenvolvidos pelo Estado, forem ignoradas. E aí impende anotar que atores tão distintos quanto Joaquín Herrera Flores e Jürgen Habermas inclinam-se na mesma direção. Enquanto Herrera Flores (2005, p. 45) fala da "exigencia de construção de lugares de encontro em que todas e todos os que participem possam fazer valer suas propostas e diferenças. Lugares de encontro de seres humanos empoderados, é dizer, de indivíduos e grupos que desfrutam de um conjunto de condições baseadas em três especificações da igualdade: igual valor, igual racionalidade e igual autoridade" ", Habermas (2011, p. 60) defende que "uma distribuição igual de direitos exclusivamente formal não pode garantir por si só a autonomia pública de todos os cidadãos. Uma 'igualdade jurídica' entendida em termos materiais igualdade em conteúdo de direitos - exige que todos possam ter as mesmas oportunidades para fazer uso, faticamente, desses direitos distribuídos de maneira igual". ${ }^{11}$ Nota-se que, com relação às condições de exercício da ação política, ambas construções teóricas exigem espaços de conversação maximamente estruturados e o compartilhamento de conteúdos comuns mínimos, com a ressalva de que sejam asseguradas condições materiais necessárias para esse exercício.

A ação política exercida nesses termos, atingidas condições materiais fundadas na igualdade, seja ela tratada como igualdade especificada ou de conteúdo de direitos e a partir da capacidade criativa do ser humano, faz possível compreender uma agenda modificadora onde o indivíduo atua como epicentro do processo político. Na valiosa síntese de Joaquín Herrera Flores, não basta negar a possibilidade de reinventar democraticamente o direito, mas antes de "não se trata de se desarmar frente a tais cumplicidades entre o jurídico e o sistema de relações sociais hegemônico, mas de afirmar nossa diferença e nossa discrepância política, social e cultural contra

distribuidos por igual. (HABERMAS, 2011, p. 60 - alguns itálicos não constam no original). Nota-se que, com relação às condições de exercício político, ambas exigem espaços de conversação maximamente estruturados e o compartilhamento de conteúdos comuns mínimos, com a ressalva de que sejam asseguradas condições materiais para esse exercício.

${ }_{10}$ No original: "Pensar los derechos humanos, desde este plano de inmanencia, nos lleva a integrar dentro de su concepto, no solo formas y procedimientos que reúnen a individuos, grupos o Estados bajo la forma de denuncias mutuas ante las Cortes Internacionales de Derechos Humanos, sino también la exigencia de construcción de lugares de encuentro en que todas y todos los que participen puedan hacer valer sus propuestas y sus diferencias. Lugares de encuentros de seres humanos empoderados, es decir, de individuos y grupos que gocen de un conjunto de condiciones basadas en tres especificaciones de la igualdad: igual valor, igual racionalidad e igual autoridad"

${ }^{11}$ No original: "Una distribución igual de derechos exclusivamente formal no puede garantizar por sí sola la autonomía pública de todos los ciudadanos. Una "igualdad jurídica” entendida en términos materiales - igualdad en el contenido de los derechos - exige que todos puedan tener las mismas oportunidades para hacer uso, fácticamente, de esos derechos distribuidos por igual."

Revista de Direito Brasileira | São Paulo, SP | v. 14 | n. 6 | p. 80 - 88 | maio/ago. 2016 
o encerramento da capacidade humana de transformar o mundo em função de novos valores e novas formas de reação diante do mundo" (FLORES, 2005, p. 47).

A tutela de direitos humanos, concebida como instrumento de busca por formas de dignidade múltiplas não contidas em um conceito total, pode, a partir da conjunção entre atingimento de condições materiais de existência e de ação política e da criatividade humana tratada em termos kierkegaardianos, ser internalizada mesmo pelo Estado de cariz burguesa. Mesmo lutas tradicionalmente suprimidas do debate político, como é o caso da realização de um projeto amplo de reforma agrária no Brasil, podem ser encampadas pelo sistema a partir de uma visão anti-hegemônica. Precisamente este é o diagnóstico de Guilherme Boulos (2015), líder do MTST (Movimento dos Trabalhadores Sem Teto) ao afirmar que “ [u]ma saída popular é defender a Constituição. Ser de esquerda no Brasil, é meio lamentável dizer isso, implica em defender pontos da Constituição, que prevê a auditoria da dívida pública, a taxação de grandes fortunas, a função social da propriedade, a democracia nas comunicações (...) Taxação de grandes fortunas se faz com correlação de forças, não se faz apenas com vontade política. Agora correlação de forças se constrói e se cria fortalecendo os movimentos sociais". Mais do que descartar a luta política a pretexto de sua inocuidade, ou de denunciar que os aparelhos institucionais funcionam sob a batuta de um sistema totalizador, é preciso que a dinâmica estatal pode ser dirigida pelo sujeito dotado de capacidade de subjetivação equipado de condições materiais de exercício de sua autonomia política.

Em contrapartida à compreensão dos instrumentos jurídicos e políticos como decorrências do sistema total, funcionalmente limitados a garantir a sobrevida do todo hegemônico, a partir de uma lógica que encadeia a ação política exercida no interior da dinâmica estatal aos fins buscados por estratos sociais detentores do poder, surge uma visão que a partir da conexão entre capacidade de criação subjetivadora e atingimento de condições materiais de exercício da ação política pretende separar o aparelho estatal das pretensões totais e hegemônicas, capaz de exclamar diante delas que: "teus caminhos não são os meus caminhos e teus pensamentos não são os meus pensamentos!” (MARX, 1998, p. 267).

\section{BIBLIOGRAFIA}

ADORNO, Theodor W. Kierkegaard: Construcción de lo estético. Madrid: Akal, 2006. Tradução de Joaquin Chamorro Mielke.

ENGELS, Friedrich. Socialismo de juristas. Crítica do Direito, São Paulo, v. 1, n. 1, p.1-4, 1980.

FLORES, Joaquím Herrera. Los derechos humanos como productos culturales: crítica del humanismo abstracto. Madrid: Catarata, 2005.

GIANNOTTI, José Arthur. Sobre Direito e Marxismo. Crítica do Direito, São Paulo, v. 1, n. 1, p.5-14, 1980.

HABERMAS, Jürgen. Verdad y justificación. Madrid: Trotta, 2011. Tradução de Pere Fabra e Luis Díez. 
KIERKEGAARD, Søren. Kierkegaard's Writings, VI: Fear and Trembling/Repetition. Princeton: Princeton University Press, 2013. Tradução de Howard V. Hong e Edna H. Hong. Ebook.

Temor e tremor. São Paulo: Hemus, 2008. Tradução de Torrieri Guimarães.

LACLAU, Ernesto. Philosophical roots of discourse theory. 2003. Disponível em: <http://www.essex.ac.uk/centres/TheoStud/onlinepapers.asp>. Acesso em: 12 dez. 2014.

MARX, Karl. O caráter fetichista da mercadoria e seu segredo. In: MARX, Karl. O capital: crítica da economia política, volume I, livro primeiro, tomo 1. São Paulo: Abril, 1987. p. 197208.

. Debates acerca do furto de lenha. In: EIDT, Celso. O estado racional: lineamentos do pensamento político de Karl Marx nos artigos da Gazeta Renana (1842 - 1843). 1998. $286 \mathrm{f}$. Dissertação (Mestrado) - Curso de Filosofia, Faculdade de Filosofia e Ciências Humanas, Universidade Federal de Minas Gerais, Belo Horizonte, 1998.

; ENGELS, Friedrich. Manifesto do Partido Comunista. São Paulo: Penguin/ Companhia das Letras, 2012. Tradução de Sergio Tellaroli.

POULANTZAS, Nicos. A Lei. Crítica do Direito, São Paulo, v. 1, n. 1, p.63-82, 1980.

ROUANET, Sergio Paulo. Adorno e Kierkegaard. Estudos Avançados, São Paulo, v. 27, n. 79, p.147-156, 2013. Disponível em: <http://www.scielo.br/scielo.php?pid=S010340142013000300011\&script=sci_arttext $>$. Acesso em: 10 dez. 2014.

RUBIO, David Sanchez. Sobre a racionalidade econômica eficiente e sacrifical, a barbárie mercantil e a exclusão dos seres humanos concretos e a natureza. Revista de Estudos Jurídicos Unesp, Franca, v. 17, n. 26, p.1-16, 2013. Disponível em: <http://seer.franca.unesp.br/index.php/estudosjuridicosunesp/article/view/1267>. Acesso em: 15 dez. 2014.

SAFATLE, Vladimir. Theodor Adorno: a unidade de uma experiência filosófica plural. In: ALMEIDA, Jorge de; BADER, Wolfgang (Org.). O pensamento alemão no Século XX: volume I. São Paulo: Cosac Naify, 2013. p. 201-227.

SCHRAG, Calvin O. Note on Kierkegaard's Teleological Suspension of the Ethical. Ethics, Chicago, v. 70, n. 1, p.66-68, out. 1959. Disponível em: 〈http://www.jstor.org/stable/2379617>. Acesso em: 20 dez. 2014. 